University of Nebraska - Lincoln

DigitalCommons@University of Nebraska - Lincoln

USDA National Wildlife Research Center - Staff Publications
U.S. Department of Agriculture: Animal and Plant Health Inspection Service

September 2004

\title{
Avian perching deterrents on ultrasonic sensors at airport wind- shear alert systems
}

\author{
Michael L. Avery \\ United States Department of Agriculture/Wildlife Services, National Wildlife Research Center, \\ michael.I.avery@aphis.usda.gov \\ Ann C. Genchi \\ United States Department of Agriculture/Wildlife Services, National Wildlife Research Center
}

Follow this and additional works at: https://digitalcommons.unl.edu/icwdm_usdanwrc

Part of the Environmental Sciences Commons

Avery, Michael L. and Genchi, Ann C., "Avian perching deterrents on ultrasonic sensors at airport windshear alert systems" (2004). USDA National Wildlife Research Center - Staff Publications. 74.

https://digitalcommons.unl.edu/icwdm_usdanwrc/74

This Article is brought to you for free and open access by the U.S. Department of Agriculture: Animal and Plant Health Inspection Service at DigitalCommons@University of Nebraska - Lincoln. It has been accepted for inclusion in USDA National Wildlife Research Center - Staff Publications by an authorized administrator of DigitalCommons@University of Nebraska - Lincoln. 


\title{
Avian perching deterrents on ultrasonic sensors at airport wind-shear alert systems
}

\begin{abstract}
Michael L. Avery and Ann C. Genchi
Abstract Preventing birds from perching on the sensor units of the Federal Aviation Administration's Low Level Wind-shear Alert System (LLWAS) is crucial to its successful operation. In this study we evaluated, under controlled conditions, responses of brownheaded cowbirds (Molothrus ater), fish crows (Corvus ossifragus), great horned owls (Bubo virginianus), barred owls (Strix varia), and black vultures (Coragyps atratus) to several anti-perching devices. No device was totally successful against every species. Of the 5 original test devices, the most effective perching deterrent was a set of 17 stout spikes ("AgSpikes") secured to the central portion of the sensor unit that point up $0^{\circ}$ to $30^{\circ}$ from the vertical. The central spikes were subsequently redesigned and combined with 9 metal bushings ( 3 for each arm of the sensor unit) that fit loosely on the sensor arms and that were armed with 5 sharp spikes each. This "AgSpikes and SpikedSpinner" combination unit was as effective as the original AgSpikes for all birds except owls, which were able to place their feet within the open spaces of the redesigned AgSpike portion of the device and perch on the 3 horizontal spikes. The combination units should adequately discourage most large and small birds from perching on LLWAS sensors. The availability of alternate perches in the field will likely enhance the effectiveness of the deterrent. Monitoring performance of the combination units deployed in the field is recommended to verify that they are working as expected.
\end{abstract}

Key words aircraft safety, barred owl, bird strike, black vulture, brown-headed cowbird, Bubo virginianus, Coragyps atratus, Corvus ossifragus, fish crow, great horned owl, Molothrus ater, perch deterrent, Strix varia

Wildlife hazards associated with airports and aircraft are an ever-increasing concern (Dolbeer et al. 2000, Cleary et al. 2003). These concerns have prompted considerable research in recent years to develop and evaluate methods for reducing the safety hazards posed by wildlife at airports. Each situation is unique, and methods such as shooting (Dolbeer et al. 1993b), habitat modification (Barras and Seamans 2002), hazing (York et al. 2000), and chemical repellents (Dolbeer et al. 1993a) can be implemented within site-specific wildlife management plans for the reduction of airport hazards (Godin 1994).
In January 2001 the Federal Aviation Administration (FAA) initiated field testing and evaluation of the Low Level Wind-shear Alert SystemRelocate/Sustain (LLWAS) at Fort Myers, Florida. Each LLWAS remote station measures wind speed and direction and transmits these data over a UHF radio link to a central LLWAS master station at the air-traffic control tower. The data are used to warn pilots of potentially dangerous local wind-shear conditions. LLWAS remote stations are mounted atop $45.5-\mathrm{m}$ poles at sites around the airport. The FAA plans to upgrade LLWAS sensors at all airports from old mechanical anemometers to new ultra-

Authors' address: United States Department of Agriculture/Wildlife Services, National Wildlife Research Center, Florida Field Station, 2820 East University Avenue, Gainesville, FL 32641, USA; e-mail for Avery: michael.l.avery@aphis.usda.gov. 
sonic anemometers. The active elements of the new units are ultrasonic transducers located in the tips of the 3 arms of the sensor unit. If horizontal airflow past these transducers is impeded, the system will not operate properly. Operation of the ultrasonic sensor is susceptible to interruption by birds that perch within the arms of the ultrasonic transducers and block the signal path.

At Fort Myers, one major problem involved vultures (Coragyps atratus) perching on one of the LLWAS units located near a wooded roost site. This problem was resolved by installing a taxidermic vulture effigy on the pole (Avery et al. 2002). The effigy did not deter other birds such as owls (Strigidae) and blackbirds (Icteridae) from perching on that sensor, however, and other sensors at the airport also experienced bird-caused failures. Furthermore, as new anemometer units are installed throughout the country, additional bird problems undoubtedly will occur. In anticipation of such events, the FAA initiated an effort to develop and evaluate bird-proof devices for installation on LLWAS units.

Numerous commercial devices are available for preventing birds from perching on structures (Hygnstrom et al. 1994). Independent evaluations of the effectiveness of such products are scarce, however. Furthermore, many available products such as sticky gels, netting, and electric shock devices are not appropriate for LLWAS sensors because they interfere with operation and maintenance of the units. Here, we report on responses of birds under controlled conditions to various candidate anti-perching measures deemed compatible with operation of the LLWAS system. Application of the findings will be widespread as the new LLWAS units are installed at airports throughout the country. In addition, the results will be useful for developing anti-perching techniques targeting problem birds in other situations.

\section{Methods}

\section{Experimental procedure}

To assess bird responses for a range of body-size classes, we tested brown-headed cowbirds (Molothrus ater), fish crows (Corvus ossifragus), great horned owls (Bubo virginianus), barred owls (Strix varia), and black vultures (Coragyps atratus). Furthermore, because wild birds exhibit substantial individual behavioral variation, we tested 4 individuals or groups of each bird species. Owls, crows, and vultures were tested individually. We tested cowbirds in groups of 3 because they often occur in flocks. Except for vultures, birds were housed and tested in $3.1 \times 3.1 \times 1.8$-m pens made of aluminum frames and plastic-coated $2.5 \times 2.5$-cm welded wire. We located the test pens in a roofed outdoor aviary; pens were equipped with water and food bowls. We mounted sensor units $1 \mathrm{~m}$ high atop a metal tripod. Sensors were operational and wired to a computer that automatically recorded failures in signal acquisition. Other than the sensor unit, the only perch available to the test birds was a tree branch placed on the floor of the pen. Vultures would not perch on the sensors in the standard test pens, so we housed and tested these birds in larger $(3.1 \times 9.2 \times 2.1-\mathrm{m})$ outdoor enclosures equipped with food and water pans and an alternate perch on the ground.

When we placed test birds into a pen, there was a 24-hour pretreatment period immediately followed by a 24 -hour treatment period. During pretreatment, birds had access to the unmodified sensor unit. Videotaping and sensor data acquisition commenced at 1200 on day $\mathbf{1}$, the pretreatment day. The videotaping ended at approximately 1800 and began again at 0730 the next morning. Sensor data acquisition was continuous. After 24 hours the candidate anti-perching device was installed. Videotaping and automatic sensor data recording continued for another 24 hours. This 48-hour sequence was repeated for each device with each test subject.

We trapped vultures, crows, and cowbirds locally, and we obtained owls from local licensed wildlife rehabilitators and veterinarians. We released or returned birds to their caretakers when testing was completed.

We reviewed each videotape and recorded to the nearest second the amount of time that birds perched on the sensor. The objective of the study was to evaluate the relative effectiveness of the various test devices for reducing data transmission failures caused by perching activity of the test species. We included, but did not emphasize, the responses of individual species. Instead, we were interested in overall effectiveness across species. Thus, we evaluated total time perched on the sensor in a repeatedmeasures analysis of variance (ANOVA) with test device and bird species as main factors and repeated measures across days (pretreatment, treatment). Sensors revealed amount of time that data transmission was interrupted by perching activity of the birds. For crows and owls, we assessed data transmission interruption time across the 24-hour pre- 

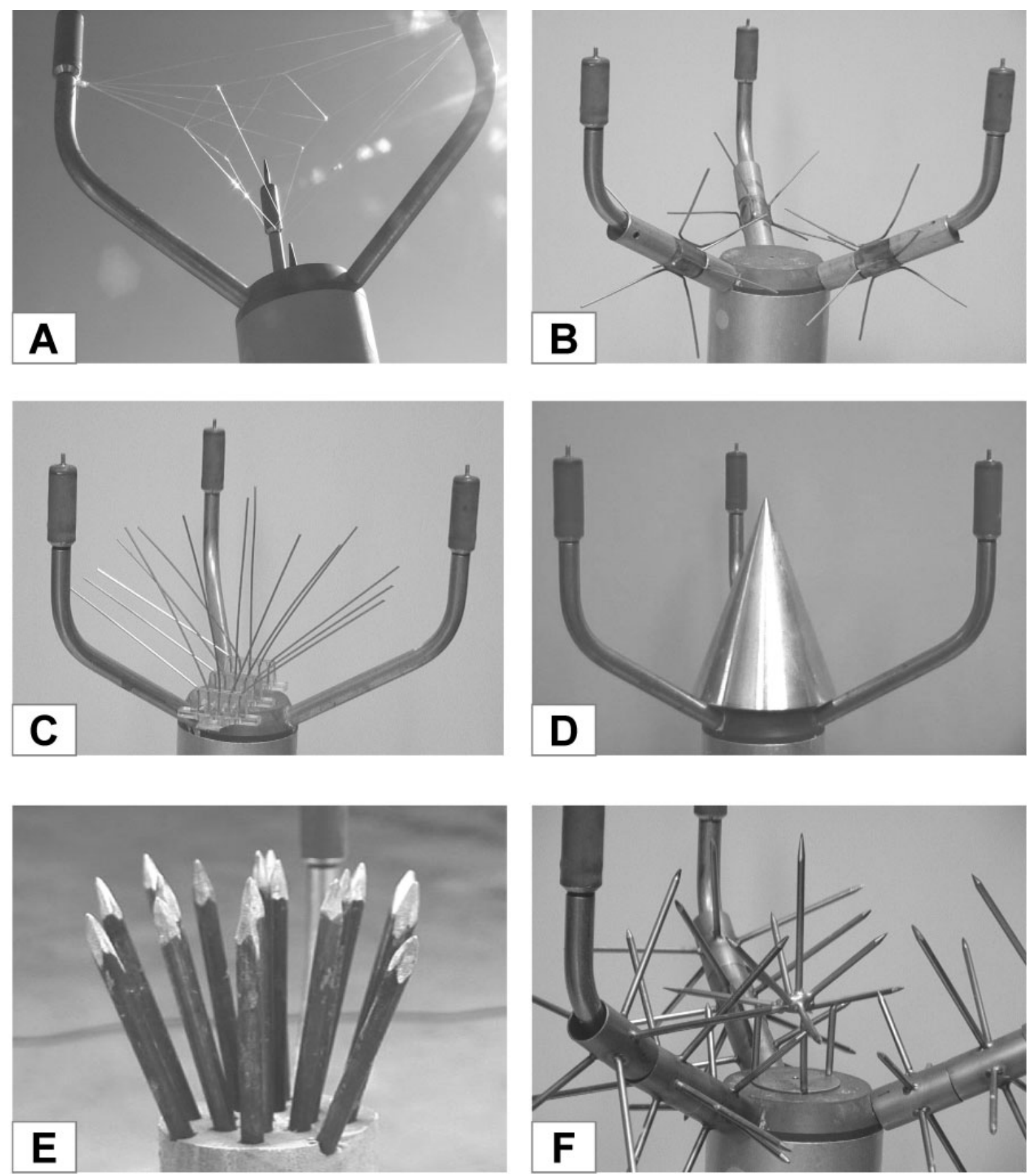

Figure 1. Anti-perching devices tested during the study, January-October 2002, Gainesville, Florida: A, monofilament web; B, bird spinners; C, bird spikes; D, AgCone; E, AgSpikes; F, combination device.

treatment and treatment periods in repeated-measures ANOVA with test device and species as main factors and repeated measures across days. For vultures there were no sensor failure data because we tested vultures in pens not wired for automatic logging of sensor transmissions.

\section{Test devices}

During initial evaluations we tested 3 devices proposed by the FAA and 2 of our own design (Figure 1). Before tests were conducted with birds, FAA personnel evaluated the devices to ensure that they would not interfere 
with normal operation of the LLWAS units.

Monofilament web. This concept required about $2 \mathrm{~m}$ of high-quality (80-pound-test) monofilament fishing line, available at most sporting-goods stores. We tied one end to one of the sensor arms just below the transducer, then strung the line to the second and third arms at the same height. From there we looped it around the center of the line spanning the 2 opposite arms and pulled it taut. We repeated the looping action around each span between the arms and finished the web by tying the end of the line to an arm.

Bird spinners. These were metal bushings (17$\mathrm{mm}$ inner diameter) that slid onto the arms of the sensor unit and covered the angled section of the arm so that birds could not perch there. Each arm received 3 bushings. The first 2 pieces installed on each arm were $2.5 \mathrm{~cm}$ long. The second piece had 6 stiff metal spines $(5 \mathrm{~cm}$ long) welded to it. The third piece was $3.7 \mathrm{~cm}$ long and, like the first piece, unarmed.

Bird spikes. These were commercially available units marketed as a means to prevent birds from perching on ledges and other surfaces. The stiff wire spines $(10.5 \mathrm{~cm}$ long) were closely packed and protruded at various angles from a central strip. We tested 12 -cm-long sections that held 3 sets of 5 spines each. We secured the spine units with a screw to the flat center part of the sensor unit.

AgCone. We milled and polished smooth a solid aluminum cone $(8.8 \mathrm{~cm}$ diameter, $11-\mathrm{cm}$ high). A short machine screw secured it to the flat central portion of the sensor unit.

AgSpikes. We inserted 17 sharpened brass rods (6.5-mm diameter, $9.5-$ to $10-\mathrm{cm}$ long), sharp end out, into holes drilled in a wooden disk $(6.3-\mathrm{cm}$ diameter, $2.5-\mathrm{cm}$ high). The spikes protruded at angles from $0^{\circ}$ to $30^{\circ}$ from vertical. We secured the unit to the flat central portion of the sensor unit with cable ties.

Following trials of these devices, we tested a sixth device, a combination unit provided by FAA contractors.

Combination Device. The AgSpike portion of the combination device consisted of 7 sharp spikes mounted on a 3.4-cm-tall pedestal connected to the sensor unit by a short screw. Three spikes (6-cm long) $120^{\circ}$ apart extended horizontally from the center. Three others (4.5- $\mathrm{cm}$ long) extended from the center upward at a $45^{\circ}$ angle midway between the longer horizontal spikes. The seventh spike (7.5-cm long) projected vertically from the center.
We installed 3 spiked spinners on each arm of the sensor unit. Each spinner was $3.7 \mathrm{~cm}$ long with a 1.7-cm inner diameter, and each held 5 sharp spikes equally spaced around the circumference perpendicular to the long axis of the spinner. Spikes on the innermost spinner were $5.2 \mathrm{~cm}$ long, those on the middle spinner were $6.0 \mathrm{~cm}$ long, and spikes on the outermost spinner were $6.5 \mathrm{~cm}$ long.

\section{Results}

\section{Data transmission failures}

No failures occurred during tests with cowbirds. Overall, mean failure time was greater $(P<0.001$, $\left.F_{1,6}=48.82\right)$ among owls ( $\left.\bar{x}=521 \mathrm{~min} / \mathrm{bird}, \mathrm{SE}=59\right)$ than crows $(\bar{x}=93 \mathrm{~min} / \mathrm{bird}, \mathrm{SE}=21)$. For crows and owls, failures were greater $\left(P=0.005, F_{1,11}=19.03\right)$ on day 1 without deterrents installed $(\bar{x}=462$ $\mathrm{min} / \mathrm{bird}, \mathrm{SE}=59)$ than with the deterrents installed on day $2(\bar{x}=152 \mathrm{~min} / \mathrm{bird}, \mathrm{SE}=38)$. The web, spikes, and the combination device eliminated crowcaused failures while the AgCone and the AgSpikes were most effective against owls (Figure 2).

\section{Perch use}

Cowbirds. Because perching activity by cowbirds resulted in no data transmission failures, we
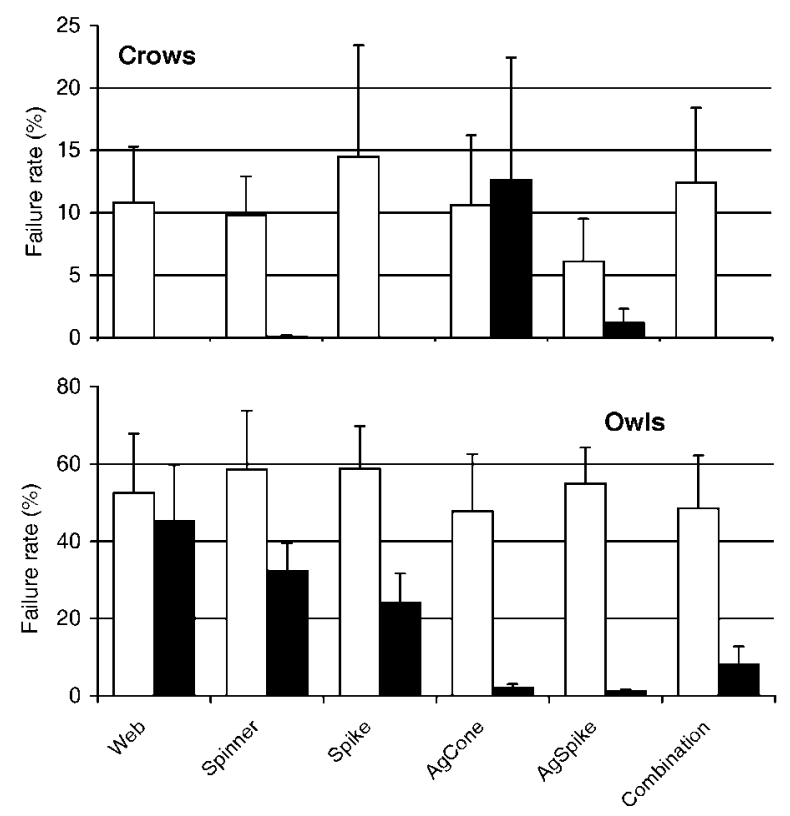

Figure 2. Low Level Wind-shear Alert System data transmission failures caused by fish crows and owls using 6 anti-perching devices during January-October 2002, Gainesville, Florida. Open bars were pretreatment means, and dark bars were mean failure rates with devices installed. Capped vertical bars denote one standard error. 


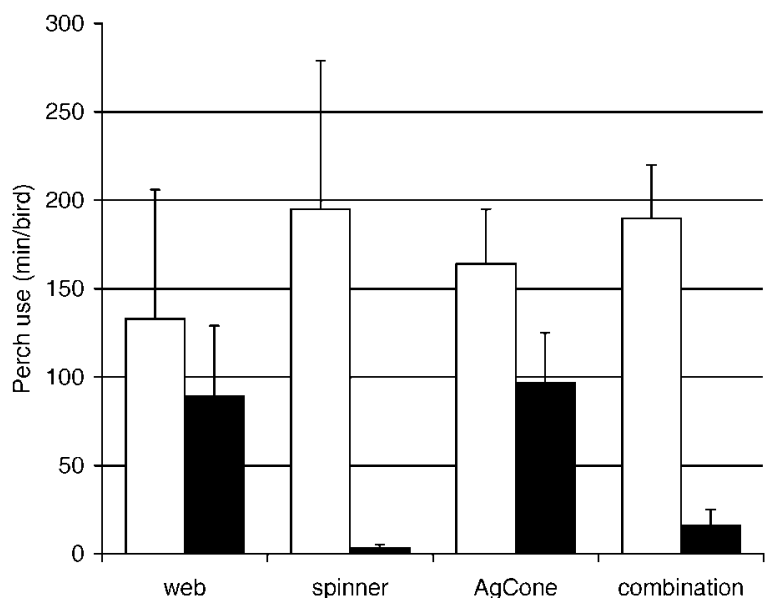

Figure 3. Perching activity by brown-headed cowbirds on Low Level Wind-shear Alert System test units equipped with 4 antiperching devices, January-October 2002, Gainesville, Florida. Light bars were pretreatment means, and dark bars were mean perching times with the test device installed. Capped vertical bars denote one standard error.

did not test cowbirds with the spike and AgSpike devices and did not include cowbirds in the statistical analysis of perch use. It was apparent, however, that the spinners inhibited cowbirds from perching on the LLWAS units (Figure 3).

Crows, vultures, owls. Across test days and test species, perch use did not vary $\left(P=0.767, F_{5,45}=\right.$ $0.51)$ among the 6 test devices. Across test devices and species, perch use decreased $\left(P<0.001, F_{1,9}=\right.$ 47.15) from day $1(\bar{x}=242 \mathrm{~min} / \mathrm{bird}, \mathrm{SE}=20)$, with no device installed, to day $2(\bar{x}=73 \mathrm{~min} / \mathrm{bird}, \mathrm{SE}=$ 17). Overall, perch use varied with species $(P=$ $\left.0.008, F_{2,9}=8.57\right)$. Owls $(\bar{x}=242 \mathrm{~min} / \mathrm{bird}, \mathrm{SE}=30)$ perched approximately twice as often as crows $(\bar{x}=$ $125 \mathrm{~min} / \mathrm{bird}, \mathrm{SE}=24)$ or vultures $(\bar{x}=106 \mathrm{~min} / \mathrm{bird}$, $\mathrm{SE}=19)$.

The only 2-way interaction was test device $\times$ test day $\left(P=0.005, F_{5,45}=3.95\right)$. Across species, reduction in perch use from day 1 to day 2 ranged from $24.8 \%$ with the web to $87.6 \%$ with the AgSpikes (Figure 4). Substantial reductions in perch use also occurred with the AgCone (86.9\%) and the combination device (81.8\%).

The 3-way interaction, device $\times$ day $\times$ species $(P$ $\left.<0.001, F_{10,45}=4.14\right)$, revealed differences in responses of species to the various test devices. For example, the web eliminated perching by fish crows, but facilitated perching by owls (Figure 5A). Owls and vultures were unable to grasp the hard, slick surface of the AgCone with their talons and thus could not maintain a stable perch. The birds

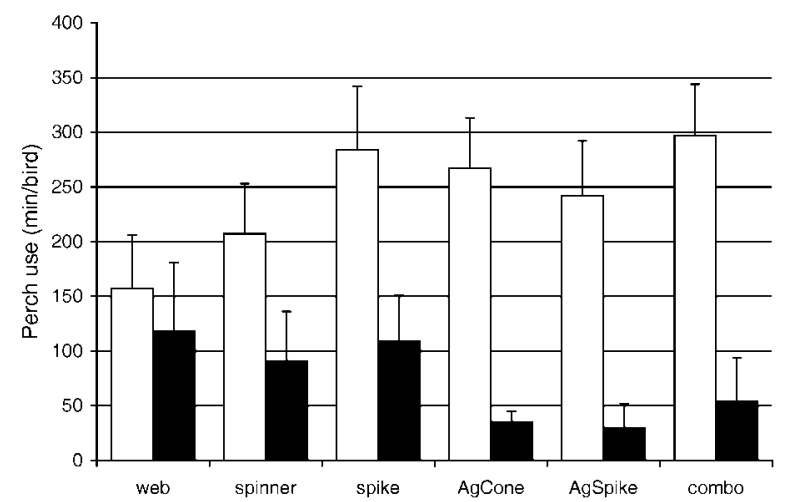

Figure 4. Combined perching activity of fish crows, black vultures, and owls on Low Level Wind-shear Alert System test units equipped with 6 anti-perching devices, January-October 2002, Gainesville, Florida. Light bars were pretreatment means, and dark bars were mean perching times with the test device installed. Capped vertical bars denote one standard error.

attempted to straddle the cone, but such a position was untenable because the distance between sensor arms was too great and the cone obstructed the bird. We also observed owls trying to perch with one foot atop the cone and the other on a sensor arm, but they could not maintain this position. Crows were able to perch on the sensor arms with the AgCone in place (Figure 5D). AgSpikes did not greatly affect crow use of the LLWAS units, but vultures and owls were deterred (Figure 5E). From videotapes it was apparent that owls could not maintain a comfortable perch on the AgSpikes. They attempted to place their feet between the spikes, but there was insufficient space. They were able to perch briefly atop the spikes but the sharpness of the spikes soon forced them off. Perching by crows was eliminated by the combination device, whereas owls were least affected (Figure 5F). Analysis of videotapes revealed that 2 owls readily perched on the central spiked portion of the assembly and rested there with little evident discomfort. Videotape analysis clearly showed that the openness of the spikes of the device enabled the owls to grasp the base of the spikes and also take advantage of the 3 horizontal spikes.

\section{Discussion}

Our findings demonstrated that no single mechanical device will prevent perching by all types of birds. Larger birds such as owls and vultures require different deterrent devices than do smaller species such as cowbirds and fish crows. 

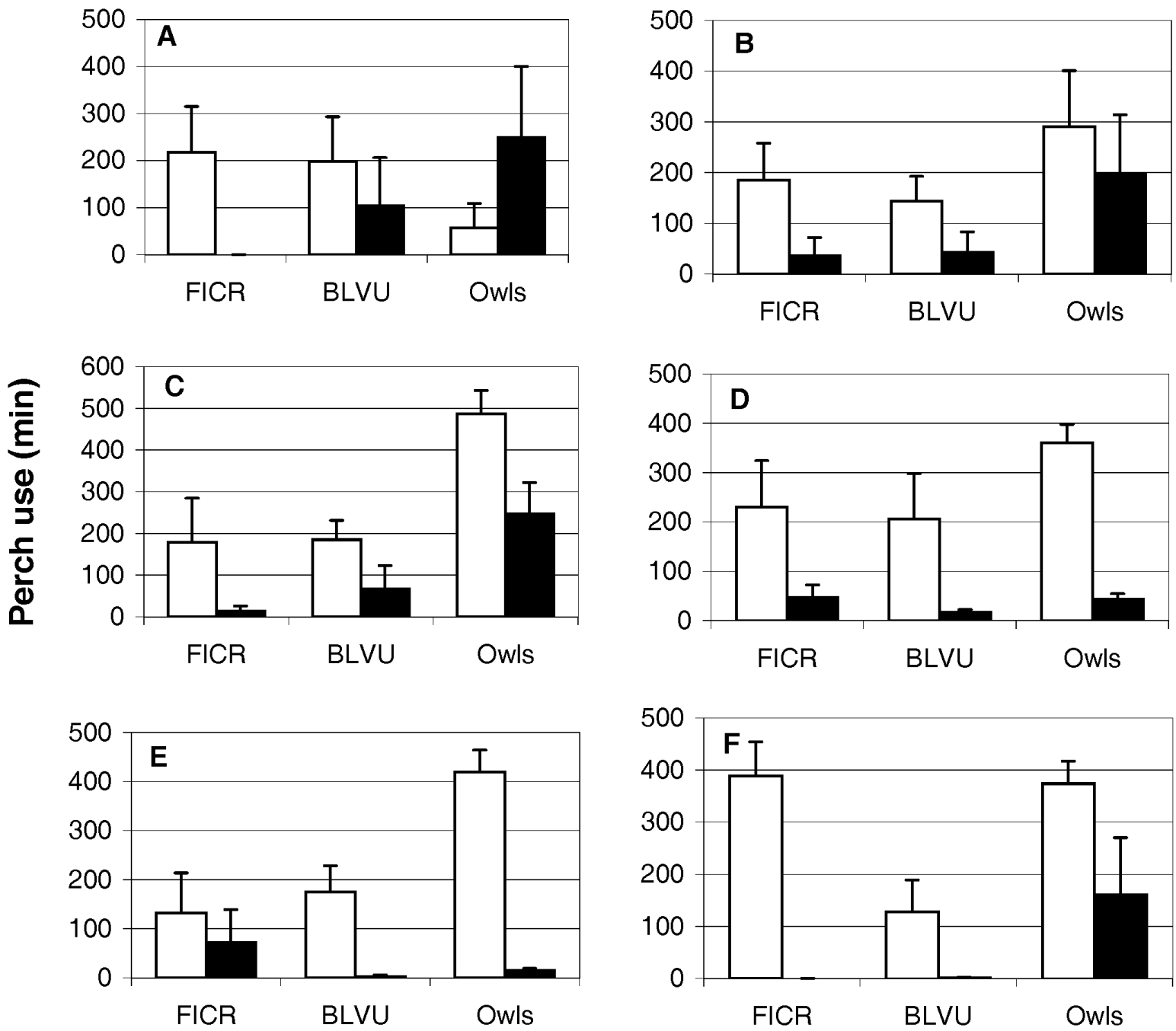

Figure 5. Perching activity by fish crows (FICR), black vultures (BLVU), and great horned and barred owls on Low Level Windshear Alert System test units equipped with (A) monofilament web, (B) bird spinners, (C) bird spikes, (D) AgCone, (E) AgSpikes, and (F) combination device, January-October 2002, Gainesville, Florida. Capped vertical bars denote one standard error.

Therefore, the most effective general approach was to combine the best large-bird deterrent with the best small-bird deterrent. Consequently, the combination device was designed and tested. This device effectively deterred most birds, but 2 barred owls persisted and were able to perch on the central spike array. Application of this device in field situations should be closely monitored to confirm its effectiveness under operational conditions.

The original AgSpike device differed markedly from the AgSpike/SpikedSpinner in the number and orientation of the spikes. The original unit consisted of 17 spikes, closely spaced and pointing upward with no more than a $30^{\circ}$ angle from the vertical. With this configuration, the birds had nowhere to perch comfortably. In contrast, the AgSpike/SpikedSpinner included 7 spikes, 3 of which were horizontal. The lower spike density and the more horizontal spike orientation of this configuration did provide perching opportunities for persistent birds. These opportunities were exploited by 2 barred owls and resulted in a data transmission failure rate of $8.1 \%$. Failure rates with owls averaged $1.3 \%$ with the original AgSpikes.

We found that perching activity did not always result in data transmission failures, especially for cowbirds and crows. Because cowbirds never caused failures, we suspect that birds of that general size will not be a problem for LLWAS units under operational conditions. Furthermore, even when 


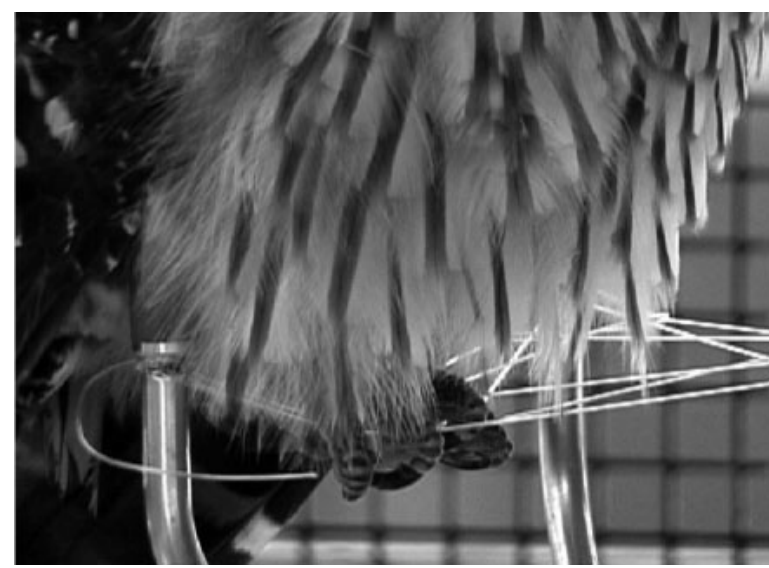

Barred owl perched on monofilament web installed on LLWAS test unit, Gainesville, Florida, April 2002.

owls perched continuously on the sensors, failures were intermittent. Slight changes in the bird's orientation on the perch affected whether or not the flow of data was interrupted.

Conditions under which perching deterrents were evaluated in this study were extreme in that test birds did not have an appealing alternative perch. Birds were forced to choose between an elevated perch on the protected sensor and a small branch at ground level. The unattractive alternative of perching at ground level probably forced some birds to persist in their use of the sensor when they

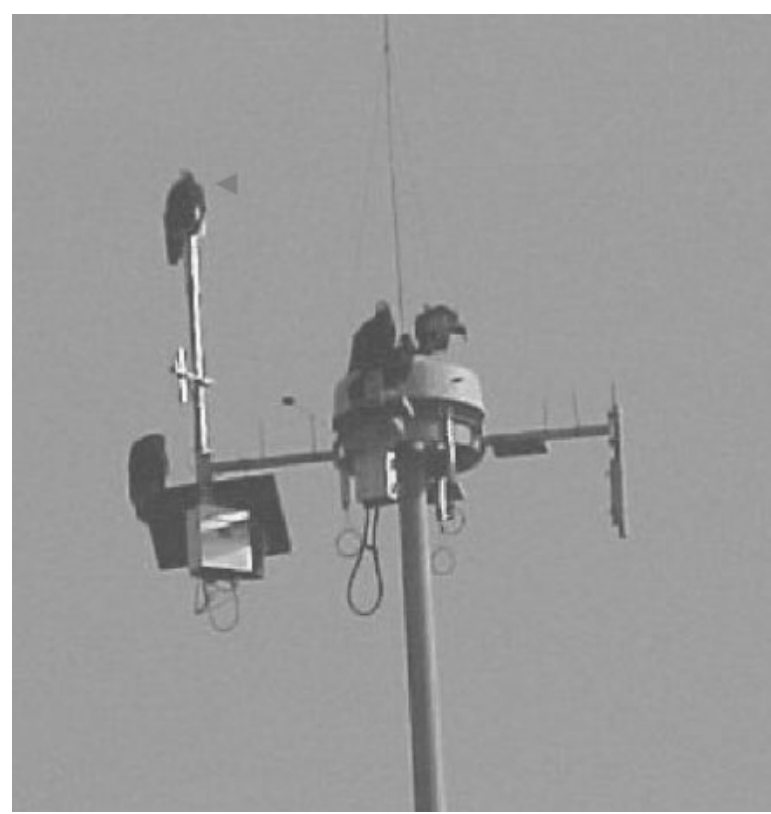

Vultures perching on LLWAS unit at the Ft. Myers, Florida airport, October 2000. Photo courtesy of Jerry Schwartz, FAA.

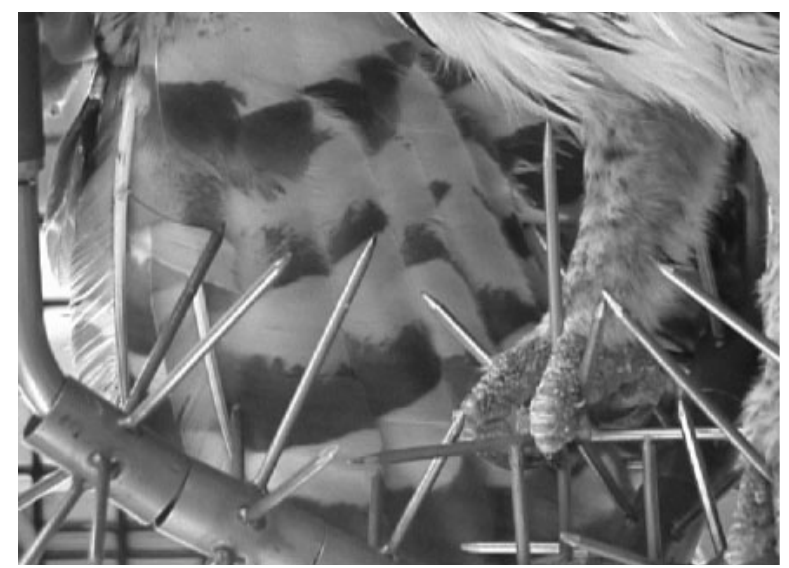

Barred owl perching on combination device installed on LLWAS test unit, Gainesville, Florida, July 2002.

would otherwise likely have abandoned the sensor for an undefended elevated perch site. Under field conditions, numerous alternate perch sites will likely be available that will increase the effectiveness of an anti-perching device installed on the sensor.

Acknowledgments. This research was conducted under FAA Agreement DTFA02-X-02016 and USDA/APHIS Agreement 02-7407-0436(IA). The study was conducted under National Wildlife Research Center approved study protocol QA-938, which included review by the animal care and use committee. We are grateful to J. S. Humphrey for designing the original AgSpike device and for arranging to have the AgCone made. M.D.Ward and M. R. Avery assisted with analyses of the videotaped observations. P. Biagi and M. Emanuel set up the LLWAS sensors and data acquisition system and provided technical support throughout. T. Brannan, L. Straub, and D. Miller supplied the owls for this study. Maintenance and care of captive birds was provided by K. L. Roca, M. D. Alderman, and W. E. Bruce.

\section{Literature cited}

Avery, M. L., J. S. Humphrey, E. A. Tillman, K. O. Phares, and J. E. HATCHER. 2002. Dispersing vulture roosts on communication towers. Journal of Raptor Research 36:45-50.

Barras, S. C., AND T. W. SEAmans. 2002. Habitat management approaches for reducing wildlife use of airfields. Proceedings Vertebrate Pest Conference 20:309-315.

Cleary, E. C., R.A. DolbeER, and S. E. Wright. 2003. Wildlife strikes to civil aircraft in the United States, 1990-2002. United States Department of Transportation, Federal Aviation Administration Serial Report No.9 DOT/FAA/AS/00-9(AAS-310). 
Dolbeer, R.A., J. L. Belant, AND L. Clark. 1993a. Methyl anthranilate formulations to repel birds from water at airports and food at landfills. Proceedings Great Plains Wildlife Damage Control Workshop 11:42-53.

DolbeER, R.A., J. L. BelanT, AND J. L. Sillings. 1993b. Shooting gulls reduces strikes with aircraft at John F. Kennedy International Airport. Wildlife Society Bulletin 21:442-450.

Dolbeer, R.A., S. E. Wright, and E. C. Cleary. 2000. Ranking the hazard level of wildlife species to aviation. Wildlife Society Bulletin 28:372-378.

Godin, A. J. 1994. Birds at airports. Pages E1-E4 in S. E. Hygnstrom, R. M.Timm, and G. E. Larsen, editors. Prevention and control of wildlife damage. Cooperative Extension Service, University of Nebraska, Lincoln, USA.

Hygnstrom, S. E., R. M. Timm, and G. E. Larsen, editors. 1994. Prevention and control of wildlife damage. Cooperative Extension Service, University of Nebraska, Lincoln, USA.

York, D. L., J. L. Cummings, R. M. ENGEMAN, AND K. L. Wedemeyer. 2000. Hazing and movements of Canada geese near Elmendorf Air Force Base in Anchorage, Alaska. International Biodeterioration \& Biodegradation 45: 103-110.
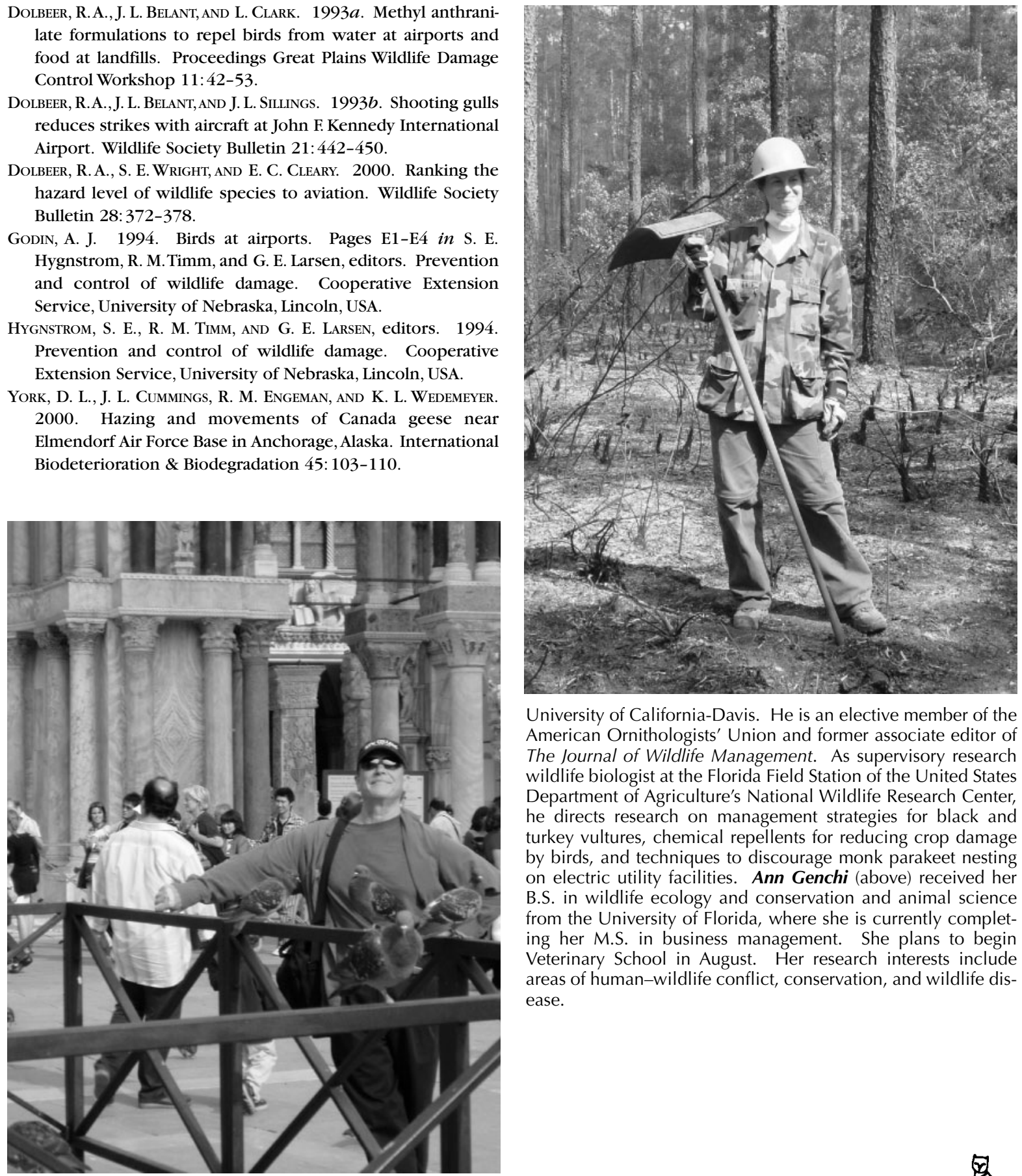

University of California-Davis. He is an elective member of the American Ornithologists' Union and former associate editor of The Journal of Wildlife Management. As supervisory research wildlife biologist at the Florida Field Station of the United States Department of Agriculture's National Wildlife Research Center, he directs research on management strategies for black and turkey vultures, chemical repellents for reducing crop damage by birds, and techniques to discourage monk parakeet nesting on electric utility facilities. Ann Genchi (above) received her B.S. in wildlife ecology and conservation and animal science from the University of Florida, where she is currently completing her M.S in business management. She plans to begin Veterinary School in August. Her research interests include areas of human-wildlife conflict, conservation, and wildlife disease.

Michael Avery (above) has an M.S. in zoology from North Dakota State University and Ph.D. in wildlife ecology from the 